\title{
Parental fat-free mass is related to the fat-free mass of infants and maternal fat mass is related to the fat mass of infant girls
}

\author{
Pontus Henriksson, Marie Löf and Elisabet Forsum
}

\section{Linköping University Post Print}

\section{Tweet}

N.B.: When citing this work, cite the original article.

Original Publication:

Pontus Henriksson, Marie Löf and Elisabet Forsum, Parental fat-free mass is related to the fatfree mass of infants and maternal fat mass is related to the fat mass of infant girls, 2015, Acta Paediatrica, (104), 5, 491-497.

http://dx.doi.org/10.1111/apa.12939

Copyright: Wiley: 12 months

http://eu.wiley.com/WileyCDA/

Postprint available at: Linköping University Electronic Press

http://urn.kb.se/resolve?urn=urn:nbn:se:liu:diva-117430 
Parental fat-free mass is related to the fat-free mass of infants and maternal fat mass is related to the fat mass of infant girls

Pontus Henriksson ${ }^{1}$, Marie Löf ${ }^{2}$ and Elisabet Forsum ${ }^{1}$

${ }^{1}$ Department of Clinical and Experimental Medicine, Linköping University, SE 58185 Linköping, Sweden.

${ }^{2}$ Department of Biosciences and Nutrition, Karolinska Institute, NOVUM, SE 14183 Huddinge, Sweden.

Short title: Body composition of parents and offspring

Correspondence: E Forsum, Department of Clinical and Experimental Medicine, Linköping University, SE 58185 Linköping, Sweden. E-mail: Elisabet.Forsum@liu.se, Phone: +46-101034743.

Abbreviation: BMI, body mass index 


\begin{abstract}
Aim: Existing studies suggest that weight and body composition of parents influence the size and body composition of their offspring, but are often inconclusive and conducted by means of inappropriate body composition methodology. Our aim was to study infant size and body composition variables in relation to body composition variables of their mothers and fathers in a well-nourished population using an accurate methodology.
\end{abstract}

Methods: Between 2008 and 2011 we used air displacement plethysmography to measure the body composition of 209 parent-infant-units. Parents were measured when women were in gestational week 32. Their healthy, singleton, full-term infants were measured at one week.

Results: Infant fat-free mass in grams was positively related $(P \leq 0.007)$ to the fat-free mass in kilograms of the mothers $(15.6 \mathrm{~g} / \mathrm{kg})$ and the fathers $(9.1 \mathrm{~g} / \mathrm{kg})$. Furthermore, the fat mass of the daughters, but not of the sons, was positively related to the fat mass of the mothers $(5.8 \mathrm{~g} / \mathrm{kg}, P=0.007)$.

Conclusion: This study found associations between the fat-free mass of parents and infants and an association between the fat mass of mothers and their infant girls. These findings may help to understand early life factors behind overweight and obesity.

Key words: body composition, father, infant, mother, sex difference

\title{
Key notes
}

- Existing studies suggest that the weight and body composition of parents influence the size and body composition of their offspring, but are often inconclusive.

- We studied body composition variables of 209 parent couples in relation to body composition variables of their infants using air displacement plethysmography.

- The findings showed associations between the fat-free mass of parents and infants and an association between the fat mass of mothers and their infant girls. 


\section{Introduction}

Overweight and obesity in early life have negative effects on human health. It has been recognised for a long time that these conditions in childhood track into adulthood (1) and many studies show that birth weight and growth during infancy are related to adult health $(2,3)$, which motivates efforts to identify determinants of early growth. Furthermore, some studies $(4,5)$, report associations between the body mass index (BMI) of mothers and infant birth weight and such an association has also been reported for fathers (6). An implication of these studies is that overweight and obesity in parents, a serious and common health problem in many populations, is positively associated with birth weight. This is a concern, since a high birth weight is associated with an increased obesity risk later in childhood and early adulthood (7). It is also relevant to note that both the weight of newborns and their body composition - their fat mass and fat-free mass - may be of interest regarding

40 obesity risk and health later in life (8). However, the effect of obesity and overweight in parents on the body composition of their infants is not well investigated. A few studies, for example (9) have reported that women with a high BMI have infants with increased body fatness. These authors (9) speculated that this increased fatness in infants born to women with a high BMI may be a risk factor for later obesity and perhaps relevant to future disease risk. However, interpretation of studies based on $\mathrm{BMI}$ is difficult, since this measure reflects both the fat mass and the fat-free mass in the body. To our knowledge, accurate methodology has not been used to study the body composition of infants in relation to the body composition of their fathers. For corresponding studies in mothers, Butte et al used such methodology in women and their infants (10) but did not identify any relationship between maternal and infant body fatness. However, this study may have been too small to identify the relatively weak relationships of relevance in a population perspective. Thus, this area requires further studies of sufficient size conducted using appropriate body composition 
methodology. The aim of this study was to investigate relationships between body

55 composition - fat and fat-free mass - of parents and their offspring.

\section{Materials and Methods}

\section{Participants and study outline}

A total of 1,530 couples from a well-educated middle-income population in

60 Östergötland, Sweden, were asked to participate in the present study when visiting a maternity health clinic because the woman was pregnant. Recruitment was conducted between 2008 and 2010 and 249 couples agreed to participate. Their body composition was assessed when the woman was in gestational week 32 , with the date based on a routine ultrasound examination in gestational week 12 , as previously described (5). The body composition of their infants was assessed at the age of one week. Only singleton and full-term infants of 37 or more gestational weeks at birth were included and we excluded 11 infants born prematurely, two who were not healthy, five who were born to a mother with preeclampsia and one born to a mother with gestational diabetes. Another 21 couples left the study. Thus the

70 study included 209 parent-infant units. Five couples conceived by means of in vitro fertilisation using their own eggs and sperm. One woman reported smoking during pregnancy. Excluding these six parent-infant units had minor effects on the results, did not alter the conclusions, and they were therefore included in the analysis. The study was conducted according to the Declaration of Helsinki and all procedures

75 involving human subjects were approved by the Ethics Committee in Linköping, Sweden. Informed consent, witnessed and formally recorded, was obtained from all parents.

\section{Measurement of parents}

80 Parents were investigated after an overnight fast. Height was measured with a wall stadiometer to the nearest $0.5 \mathrm{~cm}$. Body weight and volume, based on air 
displacement plethysmography, were assessed using Bod Pod with software 4.2.4 (COSMED USA, Inc., Concord, CA, USA) as previously described (11), and were used to calculate body density, which was converted to body composition based on the two-component model (12). For the fathers we used the fat-free mass density value $1.1 \mathrm{~g} / \mathrm{ml}(12)$ and for the women we used the value of $1.092 \mathrm{~g} / \mathrm{ml}$, published by van Raaij et al (13) and recommended for women in gestational week 32 (14). Assessment of body volume by means of air displacement plethysmography requires a correction for thoracic gas volume (12). We used the correction inherent

90 in the Bod Pod software, a procedure with only marginal effects on body composition results for men (12) or for women in gestational week 32 (11). Information regarding maternal smoking habits, parity, weight before pregnancy, gestational weight gain and education level was obtained using questionnaires administered at the time of measurement in gestational week 32 and at the infant

95 measurement. Education level was classified into primary school (nine years), high school (11-12 years) or a university degree.

\section{Infant measurement}

Infant length was assessed to the nearest $0.5 \mathrm{~cm}$ using a length board.

100 Subsequently, infants were weighed without clothing and their body volume was measured using air displacement plethysmography (Pea Pod, COSMED USA, Inc., Concord, CA, USA) (5). The Fomon model and Pea Pod software 3.0.1 were used to calculate body composition as previously described (5). Fat-free mass index was calculated as fat-free mass $(\mathrm{kg}) / \mathrm{length}(\mathrm{m})^{2}$ and fat mass index as fat mass

$105(\mathrm{~kg}) /$ length $(\mathrm{m})^{2}$. Weight-for-age and length-for-age $z$ scores were calculated using Swedish reference data (15). Infant birth weight and mode of feeding were recorded using questionnaires administered at the infant measurement. Mode of feeding was categorized into breastfeeding, breast and formula feeding or formula feeding. 


\section{Statistics}

Data were analysed using multiple regression analysis (16). Partial correlations ( $r$ ) and regression coefficients (b) were calculated with infant length, weight, fat-free mass, fat-free mass index, fat mass or fat mass index as dependent variables. Independent variables were fat mass $(\mathrm{kg})$, fat-free mass $(\mathrm{kg})$ and height of mothers

115 and fathers and, to account for important confounders, infant sex, maternal parity, infant gestational age at birth and infant age at measurement. Additional adjustments, including mode of feeding, maternal age and education level as independent variables, had only marginal effects on the results. Thus the results of such models are not shown. To identify sex differences, interaction terms were created by multiplying variables of interest by each other. Each term, for example, mothers' fat mass multiplied by infant sex, was entered separately as an additional independent variable in the appropriate regression model. Results of all tested interactions are indicated in the text. When we identified a significant interaction between mothers' fat mass and infant sex, we carried out a separate analysis with

125 fat mass and fat mass index of the boys or girls as dependent variables and maternal fat mass $(\mathrm{kg})$, fat-free mass $(\mathrm{kg})$, height, parity and infant gestational age at birth and age at measurement as independent variables. Control of regression models showed that required assumptions such as existence, independence, linearity, homoscedasticity and normality, (16) were not violated. These models had

130 no problems with multicollinearity. Differences between groups were identified using the independent t-test. $P<0.05$ was considered statistically significant. All hypothesis tests were two-sided. Statistical analysis was performed using PASW Statistics 18 (IBM, Sowers, NY, USA) or Statistica software 9.1 (StatSoft Inc., Tulsa, OK, USA). Values given are means and standard deviations (SD). 


\section{Results}

\section{Characteristics of parents and infants}

140 Parent data are presented in Table 1. Before pregnancy, six (2.9\%) women were underweight $\left(\mathrm{BMl}<18.5 \mathrm{~kg} / \mathrm{m}^{2}\right), 160(76.6 \%)$ were of normal weight $(\mathrm{BMI}=18.5-24.9$ $\left.\mathrm{kg} / \mathrm{m}^{2}\right), 32(15.3 \%)$ were overweight $\left(\mathrm{BMl}=25.0-29.9 \mathrm{~kg} / \mathrm{m}^{2}\right)$ and $11(5.3 \%)$ were obese $\left(\mathrm{BMI} \geq 30.0 \mathrm{~kg} / \mathrm{m}^{2}\right)$. One (0.5\%) father was underweight, $118(56.5 \%)$ were normal weight, 72 (34.4\%) were overweight and 18 (8.6\%) were obese. The weight

145 gain of the mothers during the entire pregnancy was $15 \pm 5 \mathrm{~kg}$. Infant data are presented in Table 2. Compared to boys, girls were significantly shorter and lighter and contained significantly more fat mass but less fat-free mass. Infants were exclusively breastfed $(94.7 \%)$ or received breast milk and formula (5.3\%).

\section{Body size and composition of infants in relation to parents' fat mass}

Table 3 shows results obtained when infant size and body composition variables were regressed on parents' fat mass. We found no significant relationships between the fat mass of the mothers or fathers, on the one hand, and infant length, weight, fat-free mass, fat-free mass index, fat mass or fat mass index, on the other hand.

155 However, a significant $(P=0.034)$ interaction between the fat mass of mothers and infant sex was found when the infants' percent fat mass was the dependent variable (Table 3). The corresponding values for infant fat mass $(\mathrm{g})$ and fat mass index were $P=0.050$ and $P=0.058$, respectively (Table 3 ). No significant interactions between the fat mass of fathers and infant sex were found for infant fat mass or fat mass index (Table 3).

For infant fat mass, the interaction between the mothers' fat mass and infant sex suggests a maternal effect that is different for sons and daughters. The relationships between the fat mass of the mothers and their infant boys and girls are shown in Table 4. The fat mass of the mothers was positively associated with fat 
165 mass and fat mass index of daughters $(P \leq 0.008)$, but not with fat mass or fat mass index of sons $(P \geq 0.77)$.

\section{Body size and composition of infants in relation to parents' fat-free mass}

Table 3 also shows the results obtained when infant size and body composition

170 variables were regressed on parents' fat-free mass. The fat-free mass of the mothers $(P=0.042)$, but not of the fathers, was positively related to infant length. Both the mothers' and fathers' fat-free mass were positively associated with weight $(P \leq 0.030)$, fat-free mass $(P \leq 0.007)$ and fat-free mass index $(P \leq 0.025)$, but not with the fat mass or fat mass index of their offspring. The fat-free mass of the parents

175 and their infants remained significantly $(P \leq 0.039)$ associated when relationships were further adjusted for infant length (Table 3). There were no significant $(P>0.10)$ interactions between mothers' or fathers' fat-free mass and infant sex for any of the relationships shown in Table 3.

180 Discussion

\section{Summation of the results}

We identified a positive relationship between maternal and infant fat mass in oneweek-old girls but no other significant relationships between fat mass of parents and their infants. We also found that fat-free mass values, adjusted for height, of both 185 mothers and fathers, were positively related to the fat-free mass of their infants. These relationships remained significant when adjusted for infant length.

\section{Comments on methodology and study population}

In this study we used air displacement plethysmography, a technique able to assess

190 body density in a valid and reliable way in human subjects with a large variation in size $(12,17)$. Such estimates can be used to calculate body composition using appropriate estimates of fat-free mass density (12). The value of $1.1 \mathrm{~g} / \mathrm{ml}$ is 
relatively accurate for the general population (12) and thus gives satisfactory results for adult male subjects. As recommended (14), we used the fat-free mass density of $1.092 \mathrm{~g} / \mathrm{ml}$, estimated by van Raaij et al (13), for women in gestational week 32 . A study in healthy Swedish women has confirmed the capacity of this value to produce satisfactory body composition results at this stage of gestation (18). A study by Ellis et al demonstrates the validity of air displacement plethysmography when assessing the body composition of infants (19). Although prediction equations may introduce

200 an error when estimating the thoracic gas volume of adult subjects, this error is small and unlikely to influence our body composition results in any important way $(11,12)$.

The parents in our study had similar BMI values - means and SDs - as those in a similar group of subjects (5). The proportions of overweight or obese women, both in the present and the previous study (5) were slightly lower than the corresponding figures for Swedish women in general. Weight and length of our infants were in agreement with Swedish reference data (15) and their body composition was similar to comparable data for Swedish infants (5). The proportion of breastfed infants was high, as is common in Sweden.

\section{Fat mass of infants in relation to fat mass of their parents}

Our observation that maternal fat mass was related to fat mass in girls but not in boys can be reconciled with previously reported results. It may well be that previous observations regarding a high body fatness of infants born to women with a high

215 BMI (9) can be explained by a relationship between maternal fat mass and fat mass in girls. It should also be noted that when boys and girls were analysed together, we did not find any significant relationships between maternal and infant fat mass, which is in agreement with the results of Butte et al (10). Furthermore, in a study on women with gestational diabetes (20), a relationship between maternal BMI and 220 infants' fat mass was found for daughters but not for sons. This sex difference may 
indicate that maternal fat mass influences male and female fetuses differently. A recent study by Roland et al (21) showed that the plasma glucose concentration of pregnant women is related to the placental weight of daughters but not of sons, an interesting finding since weight of the placenta is commonly associated with its capacity to transfer nutrients. This sex difference is of interest in relation to our findings and, as discussed by Roland et al (21), it may explain a previous observation regarding a difference between boys and girls with respect to the relationship between fasting plasma glucose of pregnant women and infant birth weight.

The significance of the observed relationship between maternal and infant fat mass in girls is unknown. Unpublished results from the present cohort show that this relationship could still be identified when the girls were 12-weeks-old, although then it was slightly weaker. This is not surprising, since many factors may influence body fatness after birth including energy intake, body weight regulation capacity and other

235 genetic and environmental factors. Few studies have investigated the relationships between body fatness at birth and later in life, and one study which did so found only a weak relationship (22). Nevertheless, the observed relationship may be important in relation to future disease risk. Thus, further follow-up is warranted to investigate relationships between mothers and daughters regarding their fat mass. In this

240 context it may be noted that periconceptional overnutrition in ewes was related to body fatness in female, but not in male offspring approaching sexual maturation (23).

\section{Fat-free mass of infants in relation to fat-free mass of their parents}

245 Our results have confirmed reports showing that the fat-free mass of mothers is positively related to the birth weight of their infants (24). Futhermore, our study contributed additional information since we demonstrated that it was the fat-free mass, rather than the fat mass, of infants that is related to the maternal fat-free 
mass. In addition, neither the relationship between fat-free mass of fathers and

250 infant birthweight, nor that between fat-free mass of fathers and of infants has been reported previously. In this context it is relevant to point out that fat-free mass is defined in terms of its contents of water, protein and mineral (19), and cannot be interpreted in terms of organs and tissues. The magnitude of the effect of parental fat-free mass on infant weight and fat-free mass was larger for mothers than for

255 fathers. The partial regression coefficients (b), relating maternal values to infant weight and fat-free mass (Table 3), were $165 \%$ and $171 \%$, respectively, of the corresponding values for fathers. A previous report showed that the weight of mothers had more influence than the weight of fathers on infant birth weight (25). We suggest that such differences between mothers and fathers are due to the intrauterine influence on fetal growth. The mechanisms linking parental fat-free mass to infants' fat-free mass are so far unknown, for mothers as well as for fathers, but it is likely that genetic factors are important.

A possible and important implication of our results is that the previously reported relationship between mothers' BMI and infant birth weight $(4,5)$ was due to

265 a large extent to an effect of the mothers' fat-free mass rather than to an effect of their fatness. We do not know the significance of our finding regarding a relationship between mothers' and infants' fat-free mass, or regarding the corresponding relationship for fathers and infants, since there are few studies reporting relationships between fat-free mass at birth and fat-free mass later in life. Crozier et 270 al reported positive relationships between fat-free mass at birth and at six-years-ofage (22) which, according to our knowledge, is the longest follow-up period of fatfree mass birth data. However, it has been shown that birth weight, which is mainly fat-free mass, is positively related to the amount of fat-free mass in the body later in life (3) a relationship that has been suggested to be the link between birth weight 275 and later obesity and cardiovascular disease, the Barker hypothesis (26). It should also be noted that a low fat-free mass index has been found to be an independent 
risk factor for all-cause mortality in adulthood (27). Therefore, it is conceivable that the relationships we have identified between parents' fat-free mass (adjusted for height) and infants' fat-free mass (adjusted for length) are important regarding 280 human health.

\section{Relevance in a population perspective}

The relationships presented in Tables 3 and 4 demonstrate the magnitude of the effect of variations in parental body composition on infant fat-free mass and fat mass. Thus fat-free mass of infants was positively related to the fat-free mass of the mothers $(15.6 \mathrm{~g} / \mathrm{kg})$ and fathers $(9.1 \mathrm{~g} / \mathrm{kg})$, while the fat mass of the infant girls was positively related to the fat mass of their mothers $(5.8 \mathrm{~g} / \mathrm{kg})$. These effects of variations in parents' body composition may appear small. However, since the variations in parents' fat-free mass and mothers' fat mass are considerable (Table

290 1) we suggest that the relationships we have identified may be potentially relevant from a population perspective, thus motivating further studies in this area.

\section{Strengths and limitations}

To our knowledge, this study is the largest to date to investigate relationships between maternal and infant body composition. Its size made it possible to identify a sex difference regarding the relationship between maternal and infant fat mass. Also, we believe it is the first to investigate relationships between body composition of fathers and their newborn infants. Other strengths are that we measured body composition instead of using BMI or skinfolds and that pregnant women and infants were measured within a narrow time frame. This is especially important in newborns, who undergo rapid changes in size and body composition $(5,15)$.

A possible limitation is that the fetus is part of the woman's body in gestational week 32. Fetal weight and fat content in gestational weeks 31-32 are approximately $1.65 \pm 0.17 \mathrm{~kg}(28)$ and $6 \%$ (29), respectively. Hence, the average 
305 contribution of fat mass, around $100 \mathrm{~g}$, from the fetus to the total fat mass of a woman at this stage of gestation is only about $0.4 \%$. The variation in fetal weight $(S D=0.17 \mathrm{~kg})(28)$ was small in relation to the variation in fat-free mass $(S D=5.3 \mathrm{~kg})$ in our women in gestational week 32 . Thus, it is unlikely that the contribution of the fetus to the fat and fat-free mass of our women affected the relationships we

310 identified in this study in any important way. It is also impossible for us to differentiate between the effects of preconceptional body composition and body composition changes during pregnancy. However, using published data (28) we found that fat mass, as a percentage as well as in $\mathrm{kg}$, and fat-free mass ( $\mathrm{kg}$ ) before pregnancy were closely correlated $(r \geq 0.9)$ to the corresponding values in week 32 . A

315 potential limitation is that some fathers in our study may not have been the biological fathers. We consider this problem unimportant since our study included collecting DNA from both parents, who were of course informed of that before participation. Furthermore, paternal discrepancy, such as when a child is identified as being biologically fathered by someone other than the man who believes he is the father,

320 is not very common, especially not in populations with high socioeconomic statuses such as ours (30). It is relevant to mention that we conducted many statistical tests, creating a risk for type one errors. Thus the sex difference regarding the relationship between maternal and infant body fatness reported in Table 4 may be the result of such an error. However, in this context it is relevant to note that the results by

325 Lingwood et al (20) can be reconciled with our findings.

\section{CONCLUSION}

In a well-nourished population we identified positive relationships between the fatfree mass of mothers, fathers and their infants. Although the study was of

330 reasonable size, we found no relationships between the fat mass of fathers and their infants, or between the fat mass of mothers and their sons. However, we identified a positive relationship between the fat mass of mothers and their daughters. The 
effects of the observed relationships are of sufficient magnitude to be potentially relevant in a population perspective and may be of help in understanding early life

335 factors behind overweight and obesity. Our results also contribute to knowledge regarding the biology of growth and development during the initial part of the human lifecycle.

\section{Acknowledgements}

340 This study was supported by grants from the Swedish Research Council (project no. 15402), the Swedish Research Council Formas (222-2006-614, 222-2008-1332), the Medical Faculty, Linköping University, and the County Council of Östergötland.

The authors thank all families participating in the study, E Rondahl and C Törnqvist for help with some of the measurements, and P Cederholm and 345 colleagues for helping with recruitment.

None of the authors declared a conflict of interest. 


\section{References}

1. Mossberg HO. 40-year follow-up of overweight children. Lancet 1989; 2:491-3.

2. Risnes KR, Vatten LJ, Baker JL, Jameson K, Sovio U, Kajantie E, et al. Birthweight and mortality in adulthood: a systematic review and meta-analysis. Int J Epidemiol 2011; 40:64761.

3. Wells JCK, Chomtho S, Fewtrell MS. Programming of body composition by early growth and nutrition. Proc Nutr Soc 2007; 66:423-34.

4. Cnattingius S, Villamor E, Lagerros YT, Wikstrom AK, Granath F. High birth weight and obesity--a vicious circle across generations. Int J Obes 2012; 36:1320-4.

5. Eriksson B, Lof M, Forsum E. Body composition in full-term healthy infants measured with air displacement plethysmography at 1 and 12 weeks of age. Acta Paediatr 2010; 99:563-8. 6. L'Abèe C, Vrieze I, Kluck T, Erwich JJ, Stolk RP, Sauer PJ. Parental factors affecting the weights of the placenta and the offspring. J Perinat Med 2011; 39:27-34.

7. Yu ZB, Han SP, Zhu GZ, Zhu C, Wang XJ, Cao XG, et al. Birth weight and subsequent risk of obesity: a systematic review and meta-analysis. Obes Rev 2011; 12:525-42.

8. Wells J. The programming effects of early growth. Early Hum Dev 2007; 83:743-8.

9. Hull HR, Dinger MK, Knehans AW, Thompson DM, Fields DA. Impact of maternal body mass index on neonate birthweight and body composition. Am J Obstet Gynecol 2008; 198:416 e1-6.

10. Butte NF, Ellis KJ, Wong WW, Hopkinson JM, Smith EO. Composition of gestational weight gain impacts maternal fat retention and infant birth weight. Am J Obstet Gynecol 2003; 189:1423-32.

11. Henriksson P, Lof M, Forsum E. Assessment and prediction of thoracic gas volume in pregnant women: an evaluation in relation to body composition assessment using air displacement plethysmography. Br J Nutr 2013; 109:111-7.

12. Fields DA, Goran MI, McCrory MA. Body-composition assessment via air-displacement plethysmography in adults and children: a review. Am J Clin Nutr 2002; 75:453-67. 
13. van Raaij JM, Peek ME, Vermaat-Miedema SH, Schonk CM, Hautvast JGAJ. New equations for estimating body fat mass in pregnancy from body density or total body water. Am J Clin Nutr 1988; 48:24-9.

14. Institute of Medicine and National Research Council. Weight gain during pregnancy reexaming the guidelines. In: Rasmussen KM, Yaktine AL, eds. Washington, D.C.: The National Academies Press, 2009:80.

15. Niklasson A, Albertsson-Wikland K. Continuous growth reference from 24th week of gestation to 24 months by gender. BMC Pediatrics 2008; 8:8.

16. Kleinbaum DG, Kupper LL, Nizam A, Muller KE. Applied regression analysis and other multivariable methods: Thomson; 2008.

17. Ginde SR, Geliebter A, Rubiano F, Silva AM, Wang J, Heshka S, et al. Air displacement plethysmography: validation in overweight and obese subjects. Obes Res 2005; 13:1232-7. 18. Forsum E, Henriksson $\mathrm{P}$, Löf $\mathrm{M}$. The two-component model for calculating total body fat from body density: An evaluation in healthy women before, during and after pregnancy. Nutrients 2014; 6:5888-5899; doi:10.3390/nu6125888.

19. Ellis KJ, Yao M, Shypailo RJ, Urlando A, Wong WW, Heird WC. Body-composition assessment in infancy: air-displacement plethysmography compared with a reference 4compartment model. Am J Clin Nutr 2007; 85:90-5.

20. Lingwood BE, Henry AM, d'Emden MC, Fullerton AM, Mortimer RH, Colditz PB, et al. Determinants of body fat in infants of women with gestational diabetes mellitus differ with fetal sex. Diabetes Care 2011; 34:2581-5.

21. Roland MCP, Friis CM, Godang K, Bollerslev J, Haugen G, Henriksen T. Maternal factors associated with fetal growth and birthweight are independent determinants of placental weight and exhibit differential effects by fetal sex. PLoS One 2014; 9:e87303.

22. Crozier SR, Inskip HM, Godfrey KM, Cooper C, Harvey NC, Cole ZA, et al. Weight gain in pregnancy and childhood body composition: findings from the Southampton Women's Survey. Am J Clin Nutr 2010; 91:1745-51. 
23. Rattanatray L, MacLaughlin SM, Kleemann DO, Walker SK, Muhlhausler BS, McMillen

IC. Impact of maternal periconceptional overnutrition on fat mass and expression of adipogenic and lipogenic genes in visceral and subcutaneous fat depots in the postnatal lamb. Endocrinology 2010; 151:5195-205.

24. Farah N, Stuart B, Donnelly V, Kennelly MM, Turner MJ. The influence of maternal body composition on birth weight. Eur J Obstet Gynecol Reprod Biol 2011; 157:14-7.

25. Griffiths LJ, Dezateux C, Cole TJ. Differential parental weight and height contributions to offspring birthweight and weight gain in infancy. Int J Epidemiol 2007; 36:104-7.

26. Singhal A, Wells J, Cole TJ, Fewtrell M, Lucas A. Programming of lean body mass: a link between birth weight, obesity, and cardiovascular disease? Am J Clin Nutr 2003; 77:726-30. 27. Bigaard J, Frederiksen K, Tjonneland A, Thomsen BL, Overvad K, Heitmann BL, et al. Body fat and fat-free mass and all-cause mortality. Obes Res 2004; 12:1042-9.

28. Olausson H, Lof M, Brismar K, Lewitt M, Forsum E, Sohlstrom A. Longitudinal study of the maternal insulin-like growth factor system before, during and after pregnancy in relation to fetal and infant weight. Horm Res 2008; 69:99-106.

29. Widdowson EM. Changes in body proportions and composition during growth. In: Davis JA, Dobbing J, eds. Scientific foundations of paediatrics. 2nd ed. Heinemann Medical Books Ltd, 1981:330-42.

30. Bellis MA, Hughes K, Hughes S, Ashton JR. Measuring paternal discrepancy and its public health consequences. J Epidemiol Community Health 2005; 59:749-54. 
Table 1. Characteristics of the 209 parent couples at the time of measurement.

Mothers Fathers

Stage of gestation ${ }^{*}$ (weeks)

$31.4 \pm 0.3$

Age (years)

$31 \pm 4$

$33 \pm 5$

Weight $(\mathrm{kg})$

$76.1 \pm 10.4^{\dagger}$

$83.0 \pm 12.3$

Height (cm)

$169 \pm 6$

$182 \pm 6$

BMI $\left(\mathrm{kg} / \mathrm{m}^{2}\right)$

$26.6 \pm 3.4^{\ddagger}$

$25.0 \pm 3.7$

Fat-free mass $(\mathrm{kg})$

$49.6 \pm 5.3$

$63.3 \pm 6.7$

Fat mass $(\mathrm{kg})$

$26.5 \pm 7.4$

$19.7 \pm 9.7$

Fat mass (\%)

$34.3 \pm 5.8$

$22.9 \pm 8.6$

Level of education§

Primary school

$0(0 \%)$

$2(1.0 \%)$

High school

$60(28.7 \%)$

$92(44.0 \%)$

University degree

$149(71.3 \%)$

$115(55.0 \%)$

Parity

0

$106(50.7 \%)$

$\geq 1$

$103(49.3 \%)$

Data are means \pm SD or $n(\%)$. BMI, body mass index.

*Based on a routine ultrasound examination in approximately gestational week 12.

† Weight before pregnancy was $66 \pm 10 \mathrm{~kg}$ (self-reported).

${ }^{\ddagger}$ BMI before pregnancy was $23 \pm 3 \mathrm{~kg} / \mathrm{m}^{2}$, calculated using self-reported weight.

$\S$ Self-reported 
Table 2. Characteristics of the infant boys and girls in the study.

$$
\text { Girls }(n=99) \quad \text { Boys }(n=110) \quad \text { All }(n=209)
$$

At birth

Weight $^{*}(\mathrm{~g})$

Gestational age (weeks)

At the time of measurement

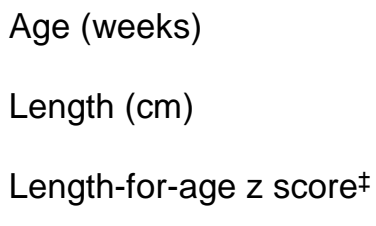

Weight (g)

Weight-for-age $z$ score $\ddagger$

Fat-free mass ( $g$ )

Fat-free mass index $\left(\mathrm{kg} / \mathrm{m}^{2}\right)$

Fat mass ( $g$ )

Fat mass index $\left(\mathrm{kg} / \mathrm{m}^{2}\right)$

Fat mass (\%)

$$
3540 \pm 460
$$$$
40.0 \pm 1.2
$$

$$
1.0 \pm 0.3
$$

$51.0^{\dagger} \pm 1.5$

$0.26 \pm 1.13$

$3523^{\dagger} \pm 445$

$-0.14 \pm 1.01$

$3049^{\dagger} \pm 318$

$11.61^{\dagger} \pm 0.79$

$474^{\dagger} \pm 171$

$1.79^{\dagger} \pm 0.59$

$13.2^{\dagger} \pm 3.6$
$3660 \pm 450$

$3600 \pm 460$

$40.1 \pm 1.2$

$40.1 \pm 1.2$

$1.0 \pm 0.3$

$51.5 \pm 1.5$

$0.18 \pm 1.10$

$3591 \pm 458$

$-0.17 \pm 1.02$

$3151 \pm 343$

$3243 \pm 339$

$11.85 \pm 0.80$

$440 \pm 183$

$1.64 \pm 0.64$

$12.0 \pm 4.0$

\section{* Reported by a parent.}

†Significantly $(P<0.05)$ different from the corresponding value for boys.

‡ Calculated using Swedish reference data (15). 
Table 3. Size and body composition variables of 209 infants at one week of age regressed on body composition variables of their parents*.

Infant variables

(dependent variables)

Length $(\mathrm{cm})$

Weight $(g)$

Fat-free mass (g)

Fat-free mass index $\left(\mathrm{kg} / \mathrm{m}^{2}\right)$

Fat mass (g)

Fat mass index $\left(\mathrm{kg} / \mathrm{m}^{2}\right)$

Fat mass (\%)
Parental variables (independent variables)

Fat mass $(\mathrm{kg})$

Fathers ${ }^{\dagger}$

Mothers $^{\dagger}$

$\begin{array}{cccccc}\mathrm{b} & \mathrm{r}^{2} & P & \mathrm{~b} & \mathrm{r}^{2} & P \\ 0.01 & 0.00 & 0.68 & -0.01 & 0.00 & 0.65\end{array}$

$\begin{array}{llllll}5.1 & 0.01 & 0.16 & -1.5 & 0.00 & 0.59\end{array}$

$\begin{array}{llllll}2.6 & 0.00 & 0.33 & -1.6 & 0.00 & 0.41\end{array}$

$\begin{array}{llllll}0.007 & 0.01 & 0.31 & -0.004 & 0.00 & 0.45\end{array}$

$\begin{array}{llllll}2.6 & 0.01 & 0.13 & 0.2 & 0.00 & 0.90\end{array}$

$\begin{array}{llllll}0.010 & 0.01 & 0.10^{* *} & 0.001 & 0.00 & 0.89^{* *}\end{array}$

$\begin{array}{llllll}0.06 & 0.01 & 0.12^{t \dagger} & 0.01 & 0.00 & 0.79^{\dagger \dagger}\end{array}$
Fat-free mass $(\mathrm{kg})$

Mothers $^{\dagger}$

Fathers $^{\dagger}$

$\begin{array}{cccccc}\mathrm{b} & \mathrm{r}^{2} & P & \mathrm{~b} & \mathrm{r}^{2} & P \\ 0.05 & 0.02 & 0.042 & 0.03 & 0.02 & 0.084 \\ 16.8 & 0.03 & 0.010 & 10.2 & 0.02 & 0.030 \\ 15.6 & 0.05 & 0.001 \ddagger & 9.1 & 0.04 & 0.007 \S \\ 0.034 & 0.04 & 0.008 & 0.020 & 0.02 & 0.025 \\ 1.2 & 0.00 & 0.68 & 1.1 & 0.00 & 0.60 \\ 0.001 & 0.00 & 0.93 & 0.002 & 0.00 & 0.81 \\ -0.02 & 0.00 & 0.76 & 0.00 & 0.00 & 0.94\end{array}$

Continued... 


\section{Table 3, continued.}

*Analysed using multiple regression analysis. Partial regression coefficient (b), coefficient of determination $\left(r^{2}\right)$ calculated from partial $r$, and the $P$ value $(P)$ are given for each relationship. Independent variables in all models are: Fat mass $(\mathrm{kg})$ and Fat-free mass $(\mathrm{kg})$ of mothers and fathers, mothers' height, fathers' height, maternal parity $(0$ or $\geq 1)$, infant sex, infant gestational age at birth and age at measurement.

${ }^{\dagger}$ Body composition (fat mass and fat-free mass) was measured when mothers were in gestational week 32 .

‡ Relationship remained significant $\left(b=9.0, r^{2}=0.03, P=0.009\right)$ when infant length was included as an additional independent variable.

$\S$ Relationship remained significant $\left(b=5.1, r^{2}=0.02, P=0.039\right)$ when infant length was included as an additional independent variable.

"Interaction terms "mothers' fat mass x infant sex" $(P=0.050)$ and "fathers' fat mass $\mathrm{x}$ infant sex" $(P=0.20)$ when interaction terms were entered separately in regression models as described in Materials and Methods.

" Interaction terms "mothers' fat mass $\mathrm{x}$ infant sex" $(P=0.058)$ and "fathers' fat mass $\mathrm{x}$ infant sex" $(P=0.19)$ when interaction terms were entered separately in regression models as described in Materials and Methods.

${ }^{\dagger \dagger}$ Interaction terms "mothers' fat mass $\mathrm{x}$ infant sex" $(P=0.034)$ and "fathers' fat mass $\mathrm{x}$ infant sex" $(P=0.30)$ when interaction terms were entered separately in regression models as described in Materials and Methods. 
Table 4. Fat mass of infant girls $(n=99)$ and boys $(n=110)$ at one week of age regressed on fat mass of their mothers ${ }^{*}$.

Infant variables

(dependent variables)

Fat mass (g)

Fat mass index $\left(\mathrm{kg} / \mathrm{m}^{2}\right)$

Fat mass (\%)
Mothers' fat mass ${ }^{\dagger}(\mathrm{kg})$

(independent variable)
Girls

b $\quad \mathrm{r}^{2} \quad P$

$\begin{array}{lll}5.8 & 0.08 & 0.007\end{array}$

$0.020 \quad 0.08 \quad 0.008$

$\begin{array}{lll}0.14 & 0.09 & 0.004\end{array}$
Boys

b $\quad \mathrm{r}^{2} \quad P$

$\begin{array}{lll}-0.6 & 0.00 & 0.79\end{array}$

$0.000 \quad 0.00 \quad 0.99$

$\begin{array}{lll}-0.02 & 0.00 & 0.77\end{array}$

*Analysed using multiple regression analysis. Partial regression coefficient (b), coefficient of determination $\left(r^{2}\right)$ calculated from partial $r$, and the $P$ value $(P)$ are given for each relationship. Independent variables in all models are: Fat mass $(\mathrm{kg})$, fat-free mass $(\mathrm{kg})$ and height of mother, maternal parity $(0$ or $\geq 1)$ and infant gestational age at birth and age at measurement. † Body composition (fat mass and fat-free mass) was measured when mothers were in gestational week 32 . 